\title{
Magnitudes de impacto e cinemática dos membros inferiores no arremesso em suspensão no handebol
}

\author{
Magnitude of lower limb impact and kinematics \\ in the handball jump throw
}

\author{
Saray Giovana dos Santos \\ Daniele Detanico \\ Diogo Cunha dos Reis ${ }^{1}$
}

1 Universidade Federal de Santa Catarina. Centro de Desportos. Laboratório de Biomecânica. Florianópolis, SC. Brasil.

Recebido em 13/07/08 Revisado em 15/12/08 Aprovado em 10/02/09
Resumo - O objetivo deste estudo foi investigar as características cinemáticas e de impacto na aterrissagem do arremesso em suspensão dos atletas amadores de handebol. Participaram deste estudo nove atletas universitários do sexo masculino. Foi utilizado um acelerômetro triaxial para identificar as magnitudes de impacto nos membros inferiores e o sistema de reconstrução tridimensional de movimento DMAS 5.0® para analisar os ângulos de flexão do joelho e quadril na aterrissagem do arremesso. Os dados da cinemática e da acelerometria foram coletados simultaneamente, sendo fixados marcadores reflexivos nos pontos anatômicos dos atletas e o acelerômetro fixado no joelho e no tornozelo dos mesmos. Para a análise dos dados utilizou-se estatística descritiva, análise de variância e correlação de Pearson com nível de significância de 5\%. As maiores magnitudes de impacto foram obtidas no tornozelo no eixo ântero-posterior $(59,81 \mathrm{~g})$. Os ângulos de flexão na fase de contato com o solo foram inferiores à fase de máxima flexão de aterrissagem, tanto para o joelho $\left(27,24^{\circ}\right.$ e $\left.33,75^{\circ}\right)$ quanto para o quadril $\left(25,77^{\circ}\right.$ e $\left.26,77^{\circ}\right)$, respectivamente. O impacto no joelho no eixo ântero-posterior possui correlação inversa com o ângulo de flexão de joelho $(\mathrm{r}=-0,64 ; \mathrm{p}=0,05)$ e quadril $(\mathrm{r}=-0,77 ; \mathrm{p}=0,01)$. A partir dos resultados pode-se enfatizar que apesar de se tratar de uma equipe amadora, devem ser adotadas medidas com intuito de aperfeiçoamento da técnica do arremesso em suspensão, a fim de minimizar os efeitos cumulativos das sobrecargas ao longo dos anos de treinamento.

Palavras-chave: Aceleração; Cinemática; Sobrecarga.

Abstract - The purpose of this study was to investigate kinematic characteristics and impact of the handball jump throw. Nine male athletes of the university team participated of this study. A tri-axial accelerometer was used for identify the impact magnitude of the lower limb and the three-dimensional analysis system DMAS 5.0® was used for the analysis knee and hip angle of the jump throw. The kinematic and accelerometry dates were simultaneously collection. Reflective markers were placed on the anatomic landmarks of the athletes and the accelerometer was placed on the knee and ankle. For the date analyses, descriptive statistics, analysis of variance and Pearson correlate were used. The level of significance was set at $5 \%$ for all tests. The biggest impact magnitudes were acquired of the anterior-posterior axle on the ankle joint (58.81 g). Knee and hip angle in the contact with ground were lesser than knee and hip angle in the maximum flexion of the lower limb $\left(27.24^{\circ}\right.$ and $33.75^{\circ}$ for knee and $25.77^{\circ}$ and $26.77^{\circ}$ for hip), respectively. The impact magnitude in the knee of the anterior-posterior axle showed inverse correlate with the knee $(r=-0.64 ; p=0.05)$ and hip angle $(r=-0.77 ; p=0.01)$ in contact with ground. From results can be conclude that, although this team to be amateur, is necessary improvement of jump throw technique to decrease of cumulative effects of overload by long time of training.

Key words: Acceleration; Kinematics; Overload. 


\section{INTRODUÇÃO}

A maioria das cargas dinâmicas geradas pelas atividades físicas, em geral, produz forças em três eixos: ântero-posterior, vertical e latero-lateral ${ }^{1}$. Nos esportes cujos fundamentos técnicos exigem saltos, essas forças, quando somadas a diferentes fatores como a exposição repetitiva aos impactos contra o solo e a deficiência técnica do executante, podem induzir a algum tipo de dano ao organismo dos atletas.

Nesse sentido, pesquisas têm relacionado características das forças resultantes dos impactos contra o solo com a ocorrência de lesões nas estruturas músculo-esqueléticas de atletas de diferentes modalidades: atletismo ${ }^{2}$ judô ${ }^{3}$ e voleibol ${ }^{4,5}$. Além disso, evidências sugerem que altas magnitudes de impacto aliadas ao super uso dos componentes biomateriais são mecanismos causadores de lesões em atletas ${ }^{6-8}$.

Em se tratando de esportes, cujos fundamentos envolvem impactos, no handebol, o arremesso em suspensão é um dos fundamentos mais utilizados em treinos e jogos ${ }^{9}$, podendo ser caracterizado por suas fases de execução: aproximação, impulsão, vôo, arremesso propriamente dito e aterrissagem ${ }^{10}$. De maneira geral, a aterrissagem é a fase de colisão contra uma superfície externa fixa, na qual o corpo é submetido a forças com rápida desaceleração (impactantes $)^{5}$. Tais forças atuam individualmente nos segmentos corporais que recebem o impacto e após são transmitidos através do sistema esquelético para o restante do corpo, podendo ocasionar choque nas articulações?.

Dessa forma, para amenizar os efeitos cinéticos dos repetidos impactos contra o solo, podem ser adotados dois mecanismos: a utilização de materiais com propriedades físico-mecânicas que favoreçam a absorção de energia (calçados com sistemas eficazes de amortecimento), ou ainda, ações relativas ao domínio da técnica na aterrissagem ${ }^{11}$.

Com relação à técnica, a fase de aterrissagem do arremesso em suspensão no handebol pode ser executada com um ou ambos os pés ${ }^{10}$. Quando executada com os dois pés, aumenta a área de contato com o solo, distribuindo as forças de impacto entre os membros inferiores ${ }^{12}$. Para Derrick ${ }^{7}$, o processo de amortecimento tem por objetivo manter o contato com o solo o maior tempo possível, a fim de dissipar a maior parte da energia para o solo, pois caso contrário, a maior parte do choque é transmitida ao organismo.

Com base nos pressupostos teóricos referidos e na busca de subsídios que possibilitem apresentar propostas para a melhoria da técnica e, consequentemente, atuar de forma preventiva é que se pretende responder a seguinte questão: quais as características das magnitudes de impacto, da altura do salto e dos ângulos de flexão dos membros inferiores na fase de aterrissagem do arremesso em suspensão no handebol?

Para responder a questão do estudo, de maneira geral, objetivou-se investigar as características cinemáticas e de impacto na aterrissagem do arremesso em suspensão dos atletas amadores de handebol da UFSC. Mais especificamente, objetivou-se identificar e comparar as magnitudes e os tempos de impacto entre os atletas, entre os eixos e entre as articulações do tornozelo e do joelho na aterrissagem do arremesso; identificar a altura do salto e caracterizar o comportamento angular do joelho e do quadril na fase de aterrissagem do arremesso; e relacionar as magnitudes de impacto do joelho e do tornozelo com a altura do salto e com os ângulos de flexão do joelho e do quadril na fase de aterrissagem do arremesso em suspensão.

\section{PROCEDIMENTOS METODOLÓGICOS}

Este estudo, inerente a um projeto macro denominado análise biomecânica em atletas de diferentes modalidades esportivas, caracterizou-se como estudo aplicado, quantitativo e de caráter exploratório.

Participaram deste estudo nove atletas de handebol do sexo masculino, integrantes da equipe universitária da UFSC, os quais apresentaram média de idade de $22,2 \pm 1,4$ anos e de tempo de prática de 7,1 $\pm 2,7$ anos, massa corporal de $83,2 \pm 10,1 \mathrm{~kg}$ e estatura de 182,0 $\pm 0,1 \mathrm{~m}$. A seleção dos sujeitos foi realizada por meio de amostragem não-probabilística intencional, adotando como critérios o mínimo de dois anos de prática na modalidade e freqüência de treino semanal de pelo menos duas vezes.

Como instrumentos de medida, foram utilizados:

a) um acelerômetro triaxial (transdutor piezoelétrico) do Tipo 4321 da Brüel \& Kjaer $^{\mathrm{TM}}$, com dimensões de $28,6 \times 28,6 \times 17 \mathrm{~mm}$, com capacidade máxima de choque de $10.000 \mathrm{~m} / \mathrm{s}^{2}$ ou $1.000 \mathrm{~g}$ (aceleração da gravidade) para medir as acelerações $\left(\mathrm{m} / \mathrm{s}^{2}\right)$ resultantes das colisões dos segmentos corporais contra o solo. A verificação dos valores de calibração do mesmo, foi realizada no Laboratório de Vibrações do EMC/ UFSC, utilizando-se: um pré-amplificador Tipo 2635 da Brüel \& $\mathrm{Kjaer}^{\mathrm{TM}}$, estando no 
ganho de $10 \mathrm{mV} \cdot \mathrm{ms}^{-2}$; um calibrador do Tipo 4294 da Brüel \& $\mathrm{Kjaer}^{\mathrm{TM}}$ e um osciloscópio IWATSU-SS-5702. Testados os três eixos ( $\mathrm{x}$, y, e z), os valores originais de calibração foram confirmados. Para a amplificação dos sinais, foram utilizados três pré-amplificadores de carga, um para cada eixo ( $\mathrm{x}$ - ântero-posterior; $y$ - vertical e z- latero-lateral) modelo $2635 \mathrm{da}$ Brüel \& KjaerTM e para a aquisição de sinais, foi utilizado o módulo MCS1000 da Lynx ${ }^{\circledR}$, composto por 16 canais de até $+10 \mathrm{~V}$, processados pelo programa de Aquisição de Sinais AqDados 7.02 e analisado pelo programa de análise AqDAnalysis 7;

b) o sistema de reconstrução tridimensional de movimento DMAS 5.0 ${ }^{\circledR}$ da SPICATek ${ }^{\circledR}$, composto por 3 câmeras filmadoras digitais DALSA-CCD ${ }^{\circledR}$ com frequência de aquisição de 40 fps, utilizado para a análise dos ângulos na fase de aterrissagem do arremesso em suspensão. Os registros videográficos foram adquiridos pelo software DMAS $5.0^{\circledR}$, com o qual as imagens foram digitalizadas para posterior reconstrução espacial do movimento. Este procedimento é realizado pelo método DLT (Direct Linear Transformation), que transforma as coordenadas bidimensionais em tridimensionais.

Os dados da cinemática e da acelerometria foram coletados simultaneamente, sendo que para a acelerometria, o acelerômetro foi fixado no joelho (sobre a articulação tibio-femural do membro inferior de aterrissagem) e no tornozelo (próximo ao maléolo externo) de cada atleta. A fixação do acelerômetro e dos cabos foi efetuada com fita elástica, de tal modo, que permitiu que os arremessos fossem realizados de forma natural e ao mesmo tempo não houve oscilação do equipamento. Para a cinemática, foram fixados marcadores reflexivos nos seguintes pontos anatômicos do membro inferior que o atleta utilizava para fazer o amortecimento do salto (aterrissagem): acrômioclavicular, trocânter maior do fêmur, epicôndilo lateral do fêmur, maléolo lateral da fíbula e cabeça do segundo metatarso.

Para as medidas dos impactos, os atletas realizaram 10 repetições com o acelerômetro fixado ora no joelho, ora no tornozelo, sendo que os valores para os cálculos das magnitudes de impacto foram obtidos a partir dos picos das curvas, utilizando como critério a magnitude do maior pico, (Figura 1), os quais foram normalizados pela massa corporal dos atletas. Para a análise dos tempos de impacto, os valores obtidos resultaram da subtração entre o tempo final e o tempo inicial de impacto (Figura 1).

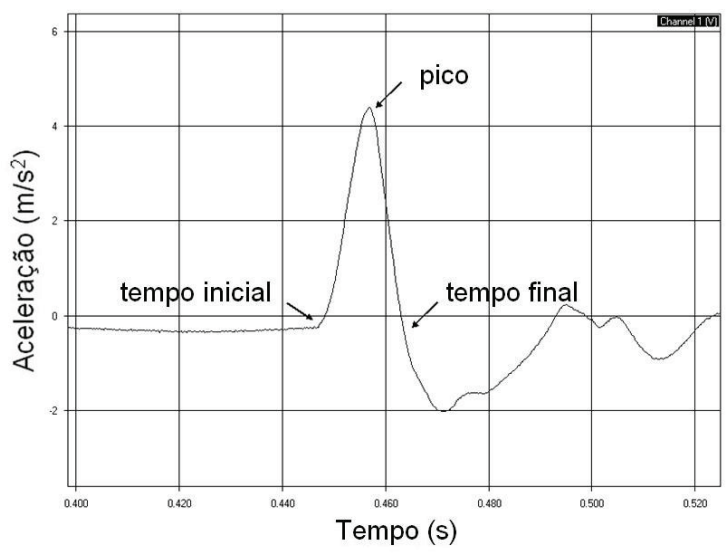

Figura 1. Critério adotado para obter o valor do pico máximo e do tempo de duração do pico em cada eixo.

Quanto as medidas para a análise cinemática dos ângulos de flexão do quadril e joelho, foram filmadas três execuções de salto com respectivas aterrissagens $\left(1^{\mathrm{a}}, 5^{\mathrm{a}}\right.$ e $\left.10^{\mathrm{a}}\right)$, nas quais, por meio da digitalização das imagens, foram identificadas a altura do salto e os ângulos de flexão do quadril e do joelho na fase de contato com o solo e na máxima flexão de aterrissagem.

Os dados foram coletados no Laboratório de Biomecânica do Centro de Desportos da Universidade Federal de Santa Catarina após assinatura no termo de consentimento livre e esclarecido, conforme exigências no Comitê de Ética em Pesquisa com Seres Humanos da UFSC, processo aprovado sob o $n^{0} 73 / 2007$.

Para o tratamento estatístico foi utilizado o teste de Shapiro-Wilk para verificar a normalidade dos dados, estatística descritiva (média, desviopadrão e coeficiente de variação); análise de variância (ANOVA multi-fatorial) seguida pelo teste Scott-Knott para a comparação das magnitudes de impacto entre eixos, articulações e sujeitos; e correlação linear de Pearson para verificar a relação entre as variáveis cinemáticas e as magnitudes de impacto. Foi adotado intervalo de confiança de 95\% para todos os testes.

\section{RESULTADOS}

As magnitudes médias de impactos obtidos na aterrissagem do arremesso em suspensão foram de: $28,24 \pm 8,09 \mathrm{~g}$ (eixo $x$ ), 12,05 $\pm 5,48 \mathrm{~g}$ (eixo $y$ ) e $18,32 \pm 5,68 \mathrm{~g}$ (eixo $z$ ) para o joelho; $59,81 \pm 22,35 \mathrm{~g}$ (eixo $x$ ), 23,08 $\pm 11,48 g$ (eixo $y$ ) e 46,20 $\pm 24,50 g$ (eixo $z$ ) para o tornozelo. Devido a variabilidade média ${ }^{17}$ 
Tabela 1. Comparação dos valores relativos de impacto (g.kg-1) entre os eixos ( $x, y$ e z), entre os sujeitos e entre as articulações na aterrissagem do arremesso em suspensão.

\begin{tabular}{|c|c|c|c|c|}
\hline ARTICULAÇÕES & SUJEITO & $x$ & $y$ & z \\
\hline & A & $0,20 \mathrm{Aa}$ & $0,06 \mathrm{Aa}$ & $0,15 \mathrm{Aa}$ \\
\hline & B & $0,33 \mathrm{Aa}$ & $0,27 \mathrm{Aa}$ & $0,38 \mathrm{Aa}$ \\
\hline & $\mathrm{D}$ & $0,35 \mathrm{Ab}$ & $0,22 \mathrm{Ab}$ & $0,16 \mathrm{Ab}$ \\
\hline \multirow[t]{5}{*}{ Impacto joelho } & $\mathrm{E}$ & $0,30 \mathrm{Ab}$ & $0,14 \mathrm{Aa}$ & 0,18 Aa \\
\hline & G & $0,40 \mathrm{Ab}$ & $0,10 \mathrm{Aa}$ & $0,15 \mathrm{Ab}$ \\
\hline & $\mathrm{H}$ & $0,34 \mathrm{Ab}$ & $0,17 \mathrm{Ab}$ & $0,33 \mathrm{Aa}$ \\
\hline & I & $0,58 \mathrm{Ab}$ & $0,17 \mathrm{Aa}$ & $0,31 \mathrm{Ab}$ \\
\hline & A & $0,36 \mathrm{Aa}$ & $0,10 \mathrm{Aa}$ & $0,26 \mathrm{Aa}$ \\
\hline \multirow[t]{5}{*}{ Impacto tornozelo } & $\mathrm{E}$ & $\mathbf{0 , 8 0} \mathrm{Ca}$ & $0,30 \mathrm{Ba}$ & $0,33 \mathrm{Aa}$ \\
\hline & $\mathrm{F}$ & $0,80 \mathrm{Ca}$ & 0,21 Aa & $0,57 \mathrm{Ba}$ \\
\hline & G & 0,89 Ca & $0,16 \mathrm{Aa}$ & 0,50 Ba \\
\hline & $\mathrm{H}$ & 1,00 Da & $0,42 \mathrm{Ba}$ & $0,54 \mathrm{Ba}$ \\
\hline & 1 & 1,19 Ва & 0,35 $\mathrm{Ba}$ & 0,86 Ca \\
\hline
\end{tabular}

Onde: letras maiúsculas diferentes mostram diferença significativa entre os sujeitos; letras minúsculas diferentes mostram diferença significativa entre as articulações e; valores em negrito mostram diferença significativa entre os eixos. $\mathrm{p} \leq 0,05$.

Tabela 2. Comparação dos tempos de impacto (s) entre os eixos (x, y e z), entre os sujeitos e entre as articulações na aterrissagem do arremesso em suspensão.

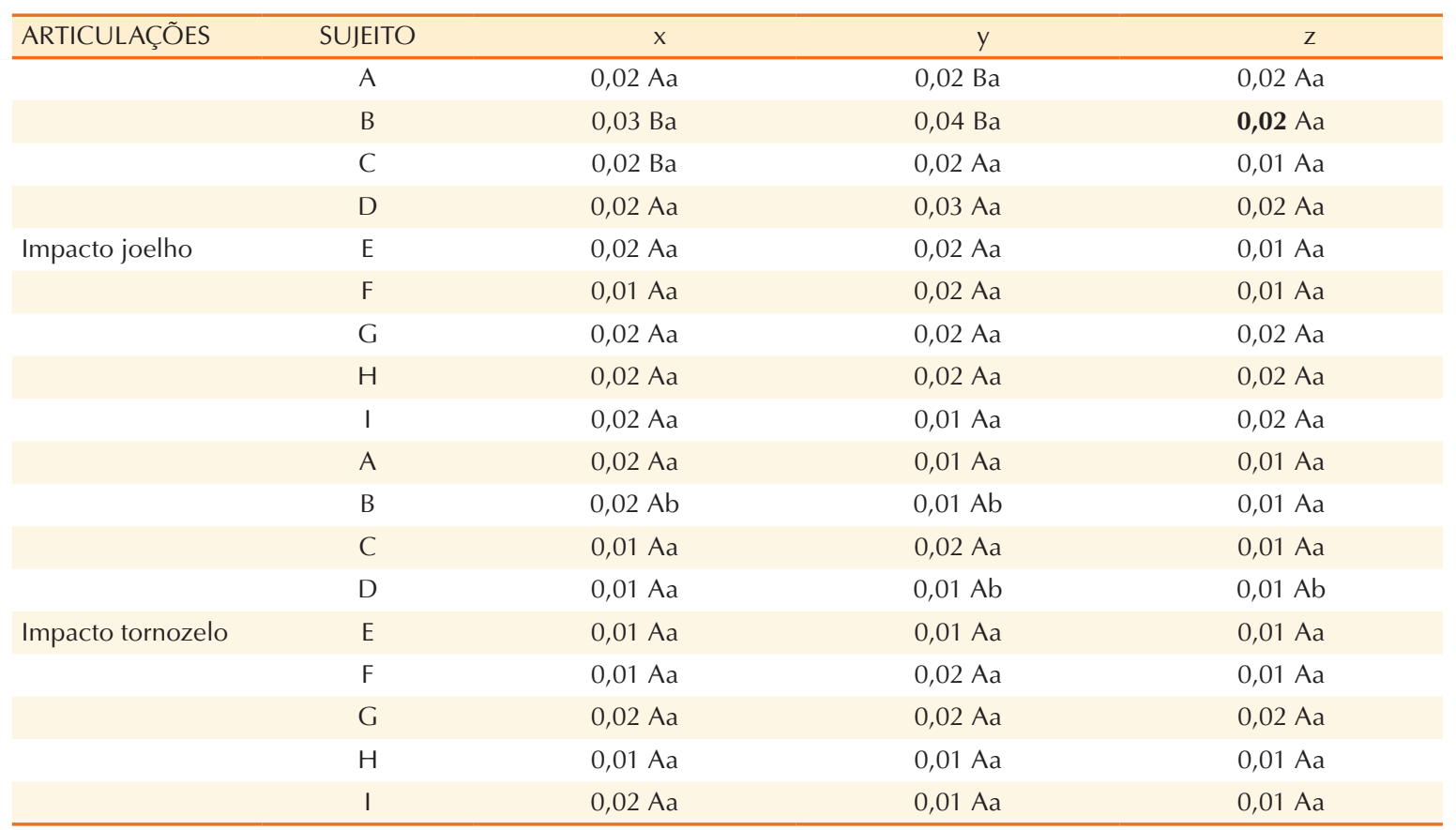

Onde: letras maiúsculas diferentes mostram diferença significativa entre os sujeitos; letras minúsculas diferentes mostram diferença significativa entre as articulações e; valores em negrito mostram diferença significativa entre os eixos.

nas massas corporais dos atletas $(\mathrm{CV}=12,1 \%)$, para comparação das forças de impacto os valores foram normalizados pela massa corporal, cujos resultados da referida comparação entre os atletas, entre os eixos e entre as articulações estão apresentados na Tabela 1.

De acordo com a Tabela 1, verifica-se que houve diferença significativa entre a maioria dos sujeitos 
apenas no tornozelo, sendo que os maiores valores significamente obtidos foram no tornozelo no eixo ântero-posterior.

Em relação aos tempos de impacto, os valores médios obtidos na aterrissagem do arremesso em suspensão foram de: 0,02 $\pm 0,003 s$ (eixo $x$ ), 0,02 $\pm 0,006 s$ (eixo y) e 0,02 $\pm 0,005 s$ (eixo $z$ ) para o

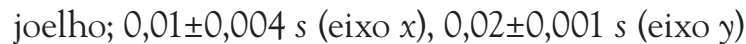
e 0,011 $\pm 0,005 s$ (eixo z) para o tornozelo. A comparação entre os atletas, entre os eixos e entre as articulações está apresentada na Tabela 2.

Observando a Tabela 2, verificam-se poucas diferenças significativas, na medida em que houve diferença apenas entre dois sujeitos no joelho; para dois sujeitos entre as articulações e para um sujeito entre os eixos.

Quanto as variáveis cinemáticas (altura do salto, ângulos de flexão de joelho e quadril), mensuradas no momento em que os atletas tocam o solo e no momento de máxima flexão, os resultados estão contidos na Tabela 3.

Observando a Tabela 3, pode-se verificar que a média da altura do salto possui pouca variabilidade, assim como os ângulos de flexão de joelho e quadril demonstrando homogeneidade nas aterrissagens. Ainda, pode-se visualizar que os ângulos de flexão de joelho e quadril, na fase de contato com o solo são inferiores a fase de máxima flexão na aterrissagem.

As correlações entre as variáveis cinemáticas obtidas com as magnitudes de impacto estão apresentadas na Tabela 4.
De acordo com a Tabela 4 verifica-se que houve correlação negativa e significativa apenas entre o impacto no joelho (eixo $x$ ) com os ângulos de flexão do joelho $(-0,64)$ e do quadril $(-0,77)$.

\section{DISCUSSÃO}

No que diz respeito às magnitudes de impacto no joelho e no tornozelo (Tabela 1) e os tempos dos eventos (Tabela 2), durante a aterrissagem do arremesso em suspensão no handebol encontraram-sese valores inferiores a $100 \mathrm{~g}$ e com tempo entre 0,01 e 0,1 s. Tais resultados, de acordo com o critério de Macaulay $^{13}$, o qual vem sendo utilizado em estudos com a mesma metodologia ${ }^{3,14,15}$, apontam para magnitudes de impactos não causadores de lesões.

Mesmo assim, as maiores solicitações observadas foram no eixo ântero-posterior, tanto no joelho quanto no tornozelo, justificado pelas características do arremesso em suspensão, sendo que o atleta executa o salto vertical com deslocamento horizontal e a aterrissagem ocorre com desequilíbrio para frente, exigindo grandes solicitações tanto muscular quanto articular.

fato dos maiores impactos terem sido obtidos no tornozelo pode ser justificado por ser a primeira articulação a receber a força impactante, além de ser o tornozelo mais estável que o joelho e realiza uma dorsiflexão para o amortecimento. Ainda, de acordo com Durward et al. ${ }^{16}$, o contato inicial do pé no solo produz um grau de carga muito rápido e forças acima de 200\% do peso corporal podem ser experimentadas.

Tabela 3. Altura do salto e valores angulares do joelho e do quadril no momento em que os atletas tocam o solo e na máxima flexão da aterrissagem do arremesso em suspensão do handebol.

\begin{tabular}{lccccc}
\hline & Altura do salto & \multicolumn{2}{c}{ Joelho $(\stackrel{\circ}{*})$} & \multicolumn{2}{c}{ Quadril () } \\
\hline & $(\mathrm{cm})$ & Toque no solo & Máxima flexão & Toque no solo & Máxima flexão \\
$\bar{x}$ & 41,51 & 27,24 & 33,75 & 25,77 & 26,77 \\
Sd & 6,51 & 10,64 & 10,92 & 10,60 & 12,68 \\
CV & 15,69 & 6,96 & 7,47 & 6,88 & 8,27 \\
\hline
\end{tabular}

Tabela 4. Correlações entre magnitudes de impacto no joelho e no tornozelo com a altura do salto e ângulos de flexão do joelho e do quadril no momento de contato com o solo.

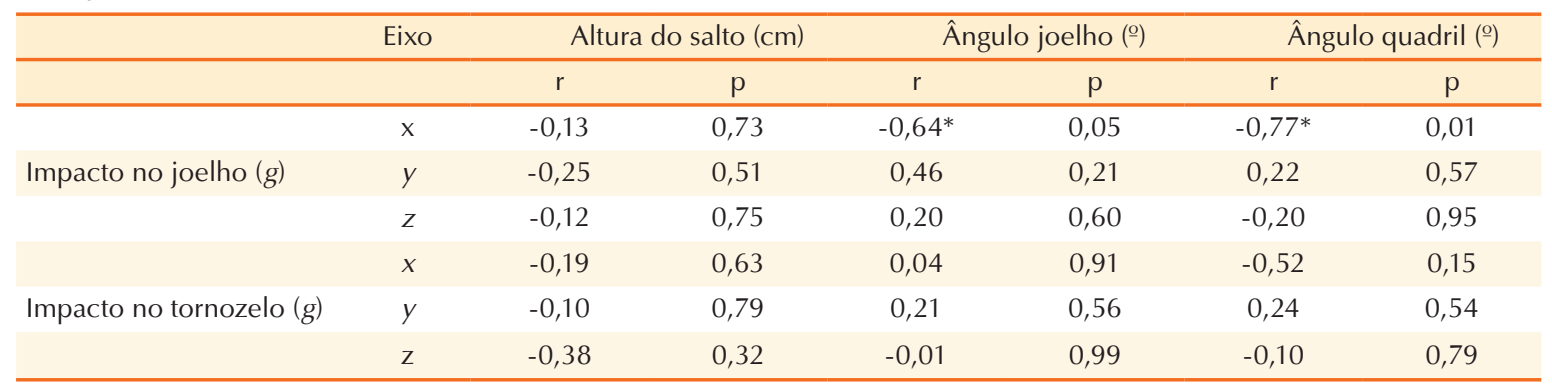

*p $\leq 0,05$ 
Os resultados obtidos neste estudo, em termos de eixos e articulações mais solicitadas, são semelhantes aos achados de Santos et al. ${ }^{15}$, ao analisarem 14 atletas amadores de voleibol do sexo masculino, utilizando um acelerômetro triaxial para mensurar as magnitudes de impacto. Os mesmos autores encontraram valores de impacto na cortada, em média de 87,88 $\mathrm{g}$ no tornozelo para o eixo ânteroposterior, o que mostra valores superiores aos achados neste estudo. É importante destacar que na aterrissagem, as maiores solicitações ocorrem no sentido ântero-posterior, pois a amenização dos impactos ocorre com o movimento de flexão dos membros inferiores ${ }^{17}$.

Com relação às comparações entre os tempos de impacto, mesmo que não significativas, os menores valores de duração do impacto foram verificados no eixo latero-lateral e no eixo ânteroposterior e, partindo do pressuposto de que quanto menores forem as durações dos impactos, maiores magnitudes o corpo pode sustentar ${ }^{13}$, os impactos por si só não acometeriam danos ao organismo, mas sim a repetitividade destes ao longo dos anos de treinamento ${ }^{18}$.

Embora não tenha sido encontrada diferença estatística com relação ao tempo de impacto, entre a maioria dos sujeitos e entre o joelho e o tornozelo, a variabilidade dos valores obtidos tanto no joelho $(\mathrm{CV}=26,9 \%)$ quanto no tornozelo $(\mathrm{CV}=30,2 \%)$, considerando os critérios de Gomes ${ }^{19}$, remete a uma equipe heterogênea, que pode ser justificada pela deficiência técnica, característica de equipes amadoras.

Quanto a altura do salto, os achados deste estudo (Tabela 3) se aproximam dos resultados verificados por Souza et al. ${ }^{20}$ ao analisarem o salto vertical contra-movimento com auxilio dos braços, utilizando uma plataforma resistiva conectada a um timer digital. Os autores analisaram 11 jogadores profissionais de handebol do Paraná, os quais atingiram, em média, 49,2 $\pm 8,1 \mathrm{~cm}$ após um período de treinamento específico. Embora se trate de saltos com características e finalidades diferenciadas, o estudo de Souza et al. ${ }^{20}$ serve como parâmetro na relação entre a altura do salto e o processo de amortecimento dos impactos nos membros inferiores, pois na tentativa de amenizar os efeitos desses impactos, as articulações dos membros inferiores são flexionadas, sendo que quanto maior a altura do salto maior a necessidade de flexionamento dessas articulações para a absorção do impacto.

Nesse sentido, foram analisados os ângulos de flexão do joelho e do quadril no momento de con- tato contra o solo (Tabela 3), sendo que os mesmos mostraram-se superiores aos encontrados em outro estudo ( $11^{\circ}$ de flexão para o joelho e $19^{\circ}$ de flexão para o quadril $)^{21}$ que analisou os ângulos de aterrissagem nos membros inferiores em atletas europeus de handebol. A flexão da extremidade inferior serve para vários propósitos, dentre eles: reduzir a quantidade de massa corporal que é envolvida na colisão inicial contra o solo; permitir que os tecidos da extremidade inferior ajam coletivamente como uma mola amortecedora para absorver as forças de impacto e/ou preparar o corpo para um movimento propulsor subsequente e; servir para reduzir as forças que atuam sobre o corpo, aumentando a distância que o centro de massa percorre enquanto essas forças agem ${ }^{1}$.

Quanto aos ângulos de máxima flexão de aterrissagem (Tabela 3), não foram encontrados estudos que quantificassem essa fase do arremesso no handebol, no entanto, os resultados verificados no momento de colisão contra o solo permitem apontar uma tendência de que os ângulos de flexão possam ser superiores aos encontrados no estudo de Krosshaug et al. ${ }^{21}$, ao analisarem atletas de uma equipe de handebol européia, dentre outras modalidades (basquetebol e esqui), por meio de análise cinemática tridimensional. Destaca-se, ainda, que a maioria dos atletas deste estudo aterrissa apenas com uma das pernas, fato este que, segundo Pappas et al..$^{12}$, inviabiliza uma maior redução do flexionamento do quadril, do joelho e do tornozelo.

As correlações negativas entre o impacto no joelho (eixo $x$ ) com os ângulos de flexão do joelho e do quadril, no momento do toque no solo ( $\mathrm{Ta}$ bela 4), podem ser justificadas pelo fato de que na aterrissagem ocorre uma interrupção brusca do movimento horizontal, aumentando a desaceleração no eixo ântero-posterior, que relacionada a ângulos de flexão maiores podem potencializar o efeito do impacto contra o solo, visto que foi o eixo que apresentou as maiores magnitudes de impacto (Tabela 1). Ainda, as maiores magnitudes de impactos estão relacionadas linearmente com os menores ângulos de flexão do joelho e do quadril.

Os achados deste estudo vão ao encontro de Lafortune et al..$^{22}$, os quais verificaram que um aumento da flexão do joelho melhora a atenuação do impacto causado pela aceleração da dorsi-flexão do pé, durante a corrida no atletismo. Não obstante, Derrick $^{7}$, ao realizar uma bateria de testes para calcular os ângulos do joelho, os picos de impacto e a força de impacto em corredores, verificou uma relação positiva entre o aumento do ângulo do joe- 
lho e o pico de aceleração em diferentes protocolos que consideravam o comprimento do passo, o tipo de piso, a intensidade e a fadiga do corredor.

Em adição, alguns estudos ${ }^{23,24}$ analisaram a cinemática angular relacionada aos impactos nos membros inferiores nos esportes, utilizando plataformas de força, mesmo assim, encontraram resultados semelhantes aos achados neste estudo. Devita e Skelly ${ }^{23}$ compararam a força de reação do solo (FRS) entre as articulações do tornozelo, do joelho e do quadril durante quedas macias (menores ângulos intersegmentares) e quedas rígidas (maiores ângulos intersegmentares) e concluíram que nas quedas macias FRS é menor, ou seja, maior é a dissipação de energia. Huston et al..$^{24}$ analisaram saltos de adultos saudáveis em diferentes alturas $(20,40$ e $60 \mathrm{~cm})$ e verificaram que quanto maior o ângulo de flexão do joelho menor é a força de reação do solo (FRS) e a sobrecarga na articulação do joelho. Ainda, há indícios de que uma técnica de aterrissagem adequada (maiores ângulos de flexão) diminui o risco de lesões ${ }^{25}$.

Embora existam diferentes fatores capazes de modular a carga de força durante a aterrissagem, esta deve ser feita a partir da ponta dos pés, pois a flexão da extremidade inferior reduz a quantidade de massa corporal que é envolvida na colisão inicial contra o solo, permitindo que os tecidos moles ajam coletivamente na absorção do impacto e automaticamente, preparem o corpo para possíveis movimentos repentinos subsequentes ${ }^{1}$.

No handebol, a fase de aterrissagem do arremesso em suspensão pode ser executada com um ou ambos os pés em contato com o solo ${ }^{10}$, no entanto, ao ser executada com os dois pés aumenta a área de contato, distribuindo as forças de impacto entre os membros inferiores ${ }^{12}$. Dessa forma, a técnica utilizada pelo atleta, entre outros fatores, interfere diretamente na cinética e na cinemática da aterrissagem e, conseqentemente, nos possíveis danos aos componentes biomateriais.

\section{CONCLUSÃO}

Com base nos resultados obtidos e respeitando as limitações do estudo pode-se concluir que:

- as maiores exigências, em termos de magnitudes dos impactos, tanto no joelho quanto no tornozelo, foram observadas no sentido ântero-posterior;

- os ângulos de flexão na fase de contato com o solo foram inferiores à fase de máxima flexão de aterrissagem, tanto para o joelho quanto para o quadril;

- quanto maior o impacto no joelho, no eixo ântero-posterior, menor o ângulo de flexão de joelho e quadril no momento de toque no solo.

Muito embora os atletas analisados tenham apresentado magnitudes e duração dos impactos considerados como níveis não causadores de lesão, os maiores valores de impacto foram encontrados no eixo ântero-posterior, apontando a sobrecarga repetida ao conjunto músculo-articulardos dos membros inferiores.

Assim sendo, tendo em vista as relações encontradas entre as magnitudes e tempos dos impactos com os ângulos de flexão do joelho e do quadril, pode-se enfatizar que mesmo sendo uma equipe amadora, para a qual há menor exigência no treinamento, quando comparada a equipes de alto nível, os responsáveis devem tomar medidas imediatas, viabilizando o aperfeiçoamento da técnica de aterrissagem, a fim de minimizar os efeitos cumulativos das sobrecargas ao longo dos anos de treinamento.

\section{REFERÊNCIAS BIBLIOGRÁFICA}

1. Simpson KJ, Ciapponi T, Wang H. Biomecânica da aterrissagem. In: Garret Jr WE, Kirkendall DT. et. al. editores. A ciência do exercício e dos esportes. Porto Alegre: Artmed; 2003. p.572-585.

2. Nigg BM, Cole GK, Bruggemann GP. Impact forces during heel-toe running. J Appl Biomech 1995;11(4):407-432.

3. Santos SG, Melo SIL, Heidrich RM, Moro ARP, Reis DC. Aceleração e tempo de duração de impacto em segmentos corporais do judoca durante a realização de ukemi em diferentes tipos de tatames. Rev Port Cien Desp 2007;7(2):156-166.

4. Gerberich SG, Luhmann S, Finke C, Priest JD, Beard BJ. Analysis of severe injuries associated with volleyball activities. Phys Sports Med 1987;15(8):75-79.

5. Santos SG, Piucco T, Reis DC. Fatores que interferem nas lesões de atletas amadores de voleibol. Rev Bras Cineantropom Desempenho Hum 2007;9(2):189-195.

6. Elliott BC. Overuse injuries in sport: a biomechanical approach. Sports Exercise (Suplemment);1999;3(1):1-6.

7. Derrick TR. The effects of knee contact angle on impact forces and accelerations. Med Sci Sports Exerc 2004;36(5):832-837.

8. Silvestre MV, Lima WC. Importância do Treinamento Proprioceptivo na Reabilitação de Entorse de Tornozelo. Fisioter Mov 2003;16(2):27-33.

9. Moraes AM, Bechis MJ, Siqueira R. Tipos de impulsões utilizadas no arremesso em suspensão no handebol (resumo). I Congresso de Ciência do Desporto. Campinas: 2005, p.21. 
10. Pori P, Bon M, Sibila M. Jump shot performance in team handball: a kinematic model evaluated on the basis of expert modelling. Kinesiology 2005;37(1):40-49.

11. Santos SG, Melo SIL. Biomecânica aplicada ao judô. In. Franchini E. Organizador. Judô Desempenho Competitivo. São Paulo: Manole; 2001, p.97-125.

12. Pappas E, Hagins M, Sheikhzadeh A, Nordin M, Rose D. Biomechanical differences between unilateral and bilateral landings from a jump: gender differences. Clin J Sport Med 2007;17(4):263-268.

13. Macaulay M. Introduction to impact engineering. London: Chapman and Hall; 1987.

14. Piucco T, Santos SG. Relação entre percentual de gordura corporal, desempenho no salto vertical e impacto nos membros inferiores em atletas de voleibol. Fit Perf J 2008; 8(1):9-15.

15. Santos SG, Esteves AC, Leite RM, Oliveira VHF, Chagas L. Características de impacto de membros inferiores e lesões em atletas de voleibol. X Congresso Brasileiro de Biomecânica. João Pessoa; 2005. p.1-5.

16. Durward BR, Baer GD, Rowe PJ. Movimento funcional humano: mensuração e análise. São Paulo: Manole; 2001.

17. Prapavessis H, McNair PJ. Effects of Instruction in Jumping Technique and Experience Jumping on Ground Reaction Forces. J Orthop Sports Phys Ther 1999; 29(6):352-356.

18. Radin EL, Paul IL, Rose RM. Role of mechanics factors in pathogenesis of primary osteoarthritis. Lancet 1972; 4(1):519-522.

19. Gomes FP. Curso de estatística experimental. 13 ed. Piracicaba: Nobel AS; 1990.

20. Souza J, Gomes AC, Leme L, Silva SG. Alterações em variáveis motoras e metabólicas induzidas pelo treina- mento durante um macrociclo em jogadores de handebol. Rev Bras Med Esporte 2006; 12(30):129-134.

21. Krosshaug T, Slauterbeck JR, Engebretsen L, Bahr R. Biomechanical analysis of anterior cruciate ligament injury mechanisms: three-dimensional motion reconstruction from video sequences. Scand J Med Sci Sports 2006; 17(5): 508-519.

22. Lafortune MA, Hennig EM, Lake MJ. Dominant role of interface over knee angle for cushioning impact loading and regulating initial leg stiffness. J Biomech 1996; 29(12):1523-1529.

23. Devita P, Skelly WA. Effect of landing stiffness on joint kinetics and energetics in the lower extremity. Med Sci Sports Exerc 1992; 24(1):108-115.

24. Huston LJ, Vibert B, Ashton-Miller JA, Wojtys EM. Gender differences in knee angle when landing from a drop-jump. Am J Knee Surg 2001; 14(4):215-220.

25. Lafortune MA. Jumping mechanics and jumper's knee. Sports Sci Med 1985; 2(2): 2-4.

\section{Endereço para correspondência}

Saray Giovana dos Santos

Universidade Federal de Santa Catarina, UFSC

Centro de Despostos - Departamento de Educa-

ção Física

Programa de Pós-Graduação em Educação Física. 88040-900 - Florianópolis, SC. Brasil

E-mail: saray@cds.ufsc.br 